\title{
Resveratrol enhanced anticancer effects of cisplatin on non-small cell lung cancer cell lines by inducing mitochondrial dysfunction and cell apoptosis
}

\author{
LIJIE MA ${ }^{1 *}$, WANGPING LI ${ }^{1 *}$, RUIXUAN WANG $^{1}$, YANDONG NAN $^{1}$, \\ QINGWEI WANG ${ }^{2}$, WEI LIU ${ }^{3}$ and FAGUANG JIN ${ }^{1}$ \\ Departments of ${ }^{1}$ Respiration and ${ }^{2}$ Pharmacy, Tangdu Hospital, Fourth Military Medical University, Xi'an 710038; \\ ${ }^{3}$ Department of Respiration, The 302 Hospital of Chinese PLA, Beijing 100039, P.R. China
}

Received June 2, 2015; Accepted July 9, 2015

DOI: $10.3892 /$ ijo.2015.3124

\begin{abstract}
Resveratrol is a plant-derived natural compound which possesses potential anticancer properties. However, there are scarce reports on its anticancer effects in non-small cell lung cancer and its auxiliary function on the anticancer effects of cisplatin. In the present study, we investigated the effects of resveratrol on the cell viability and apoptosis in human non-small cell lung cancer H838 and H520 cell lines. It has been found that resveratrol inhibited the proliferation of H838 and H520 cells in a dose- and time-dependent manner, and apoptosis was increased in cells treated with resveratrol which was associated with the depolarization of mitochondrial membrane potential, release of cytochrome $c$ from mitochondria to cytosol, and abnormal expression of Bcl-2 and Bax proteins. Above all, resveratrol enhanced the effects of cisplatin on inhibition of cancer cell proliferation, induction of cell apoptosis, depolarization of mitochondrial membrane potential, release of cytochrome $c$ and regulation on expression of Bcl-2 and Bax. Results from the present study demonstrated that resveratrol exhibited its anticancer effects on non-small cell lung cancer H838 and H520 cell lines, and enhanced the antitumor effects of cisplatin by regulating the mitochondrial apoptotic pathway. These results have put forward the rationale for further basic research and preclinical investigation on the anticancer effects of resveratrol against human non-small cell lung cancer.
\end{abstract}

Correspondence to: Professor Faguang Jin, Department of Respiration, Tangdu Hospital, Fourth Military Medical University, Xi'an 710038, P.R. China

E-mail: jinfag@fmmu.edu.cn

Professor Wei Liu, Department of Respiration, The 302 Hospital of Chinese PLA, Beijing 100039, P.R. China

E-mail: liuwei302@126.com

*Contributed equally

Key words: non-small cell lung cancer, resveratrol, cisplatin, mitochondrial dysfunction, cell apoptosis

\section{Introduction}

Lung cancer is one of the most frequent causes for cancerrelated death all over the world (1) and non-small cell lung cancer (NSCLC) accounts for $\sim 85 \%$ of lung cancer cases, which can be classified as squamous cell carcinoma (SC), adenocarcinoma (AC), large cell carcinoma, and bronchoalveolar carcinoma (BAC) (2). First-line therapeutic adoptions for all the cell types of lung cancers consist of surgery and chemotherapy, and platinum based combined chemotherapy remains the most frequently adopted therapy for patients with advanced NSCLC (3). Although there are other targeted therapy strategies, such as monoclonal antibodies and small molecule tyrosine kinase inhibitors, only a minimal survival advantage has been observed and $\sim 90 \%$ of NSCLC patients die within 5 years of diagnosis (4). Therefore, novel therapeutic agents and measures with high antitumor efficiency need continuous investigation.

Resveratrol (3,4',5-trihydroxystilbene) is a phytochemical which abundantly exists in natural foods, such as grapes, red wine, berries and peanuts, and Chinese herbal medicine, such as Polygonum cuspidatum, Veratrum nigrum and Cassia obtusifolia (5). Basic research and clinical application have suggested that resveratrol possesses a wide spectrum of biological and pharmacological effects due to its multiple hydroxyls (structure shown in Fig. 1). It has also been considered that resveratrol would be an ideal alternative drug in the therapy of cancers and cardiovascular diseases $(6,7)$. Research on the anticancer effects revealed that resveratrol induces cell cycle arrest by deregulating expression of cyclin D1, increasing cancer suppressors, such as p53 and cdk inhibitor p21 (8), and modulating expression of protein kinase C (PKC) (9). It has been confirmed that resveratrol induced cell apoptosis by interfering with expression and function of Bcl-2 phosphorylation (10), Bax mitochondrial translocation (11) and inhibition of DNA synthesis (12). However, anticancer effects of resveratrol on NSCLC are complicated and further investigations are needed in order to illustrate how resveratrol exhibited its anticancer effects in NSCLC.

Various agents exhibit their anticancer effects mainly through cell cycle arrest and cell apoptosis induction, and apop- 
tosis was induced by cell death receptor-mediated extrinsic pathway and mitochondrial mediated intrinsic pathway which can be triggered by various stimuli, such as reactive nitrogen species (RNS), reactive oxygen species (ROS), cell-cell interaction, hormones, growth factor withdrawal, antigens and chemotherapeutics. It has been widely reported that natural products and agents could induce cell apoptosis by disturbing the balance between the production of ROS and the depletion of glutathione (GSH). The imbalanced redox status could further open the mitochondrial permeability transition pore (PTP) which may lead to depolarization of mitochondrial membrane $(\Delta \Psi \mathrm{m})$. Then, cytochrome $c$ is released into cytosol followed by activation of caspase- 3 and apoptotic cell death $(13,14)$

Taking the above into account, we hypothesized that resveratrol treatment could facilitate the anticancer effects of cisplatin on depolarization of mitochondrial membrane and release of cytochrome $c$ followed by abnormal activation of apoptotic regulators and cell death. In order to evaluate this hypothesis, we investigated the effects of resveratrol combined with or without cisplatin on mitochondrial membrane potential as well as following signaling pathways in H838 and H520 cells. Results from the present study showed that resveratrol induced cell apoptosis in NSCLC cell lines and enhanced the anticancer effects of cisplatin via activation of mitochondrial intrinsic apoptosis cascade.

\section{Materials and methods}

Cell lines and culture. Human lung cancer cell lines, H838 and H520, were purchased from the American Type Culture Collection (ATCC, USA). the two cell lines were maintained in RPMI-1640 containing 10\% fetal calf serum (Gibco BRL, Grand Island, NY, USA) in a humidified atmosphere containing $5 \% \mathrm{CO}_{2}$ at $37^{\circ} \mathrm{C}$. All experiments were carried out with cells in logarithmic phase.

Cell growth inhibition assay. The effects of resveratrol on cell viability were determined by microculture tetrazolium (MTT) assay. Briefly, H838 and H520 cells were seeded in 96-well plates at a density of $1 \times 10^{4}$ cell/well and treated with various doses of resveratrol or cisplatin for $24 \mathrm{~h}$. After that selected dosage of resveratrol and cisplatin were used in H838 and H520 cells for 24, 48 and 72 h. Finally, the two cell lines were treated with combined usage of resveratrol and cisplatin. Following these treatments, cells were further incubated with MTT $(5 \mathrm{mg} / \mathrm{ml}$, dissolved in PBS and filtered through a $0.22-\mathrm{mm}$ membrane) at $37^{\circ} \mathrm{C}$ for $4 \mathrm{~h}$ before DMSO was added into each well to dissolve farmazan crystals, and the absorbance of each well was determined at $492 \mathrm{~nm}$ on an automated Bio-Rad 550 micro-plate reader (Bio-Rad Laboratories Ltd., Shanghai, China).

Examination of morphological changes of cells. $\mathrm{H} 838$ and H520 cells were seeded in a 24-well plate and then stimulated with resveratrol and/or cisplatin for $24 \mathrm{~h}$. The images of the cells were captured with an inverted microscope at 10x10 magnification (DMI6000B, Leica, Germany). Changes of cell morphology indicated cytotoxicity of resveratrol on H838 and H520 cells.

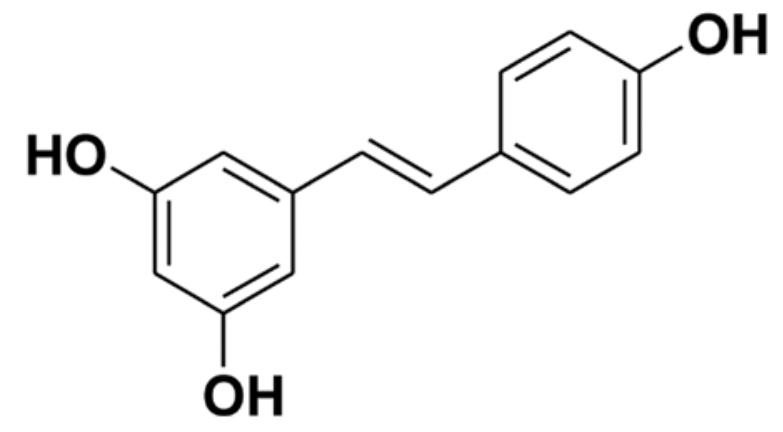

Figure 1. The structure of resveratrol.

Measurement of mitochondrial membrane potential (MMP). Tetrechloro-tetraethylbenzimidazol carbocyanine iodide (JC-1, Beyotime Institute of Biotechnology, China) is a mitochondrial-specific cationic dye, it is a monomer when the mitochondrial membrane potential is $<120 \mathrm{mV}$ and emit a green light $(540 \mathrm{~nm})$ following excitation by blue light (490 nm). JC-1 was used, in the present study, to evaluate the changes of MMP in H838 and H520 cells with or without stimulation of resveratrol, cisplatin or combined usage of the two agents. Briefly, cells were seeded in a 24 -well plate at the density of $2 \times 10^{5}$ cell per well, and incubated with $5 \mu \mathrm{M}$ JC-1 for $30 \mathrm{~min}$ after challenge by resveratrol and cisplatin. Finally, fluorescence was captured with the inverted fluorescence microscope and changes in fluorescence intensity ratio between the measurements at wavelengths of 590 (red) and $540 \mathrm{~nm}$ (green) were used to evaluate the mitochondrial membrane potential.

Cell apoptosis analysis by flow cytometry. The apoptotic rate of H838 and H520 cells challenged with or without resveratrol and cisplatin was detected by flow cytometry using Annexin V-FITC/PI staining (KeyGen Biotech, Jiangsu, China). Briefly, cancer cells were seeded and incubated in 6-well plates and treated with resveratrol and/or cisplatin for $24 \mathrm{~h}$. After that, cells were collected, washed with PBS and resuspended in binding buffer containing PI and Annexin V-FITC and incubated at room temperature in the dark for $15 \mathrm{~min}$ according to the manufacturer's instructions. Finally, cells were analyzed by flow cytometer (BectonDickinson, San Jose, CA, USA).

Western blot analysis. The extraction of cytosolic and total proteins of the cells from different groups was carried out according to instructions of protein extraction kit (Beyotime Institute of Biotechnology, Jiangsu, China). Protein concentrations were determined by BCA method with an assay kit (Beyotime). Equal amount of proteins from each group were electrophoresed on $12 \%$ SDS-PAGE before transferring to PVDF membrane (Millipore, MA, USA). The membrane was then blocked with $5 \%$ (w/v) non-fat milk and washed with Tris-buffered saline-Tween solution (TBST). Then, the membranes were incubated overnight at $4^{\circ} \mathrm{C}$ with primary antibodies according to the manufacturer's instructions. After being washed with TBST, membranes were further incubated with secondary antibody at room temperature for $2 \mathrm{~h}$. Finally, 

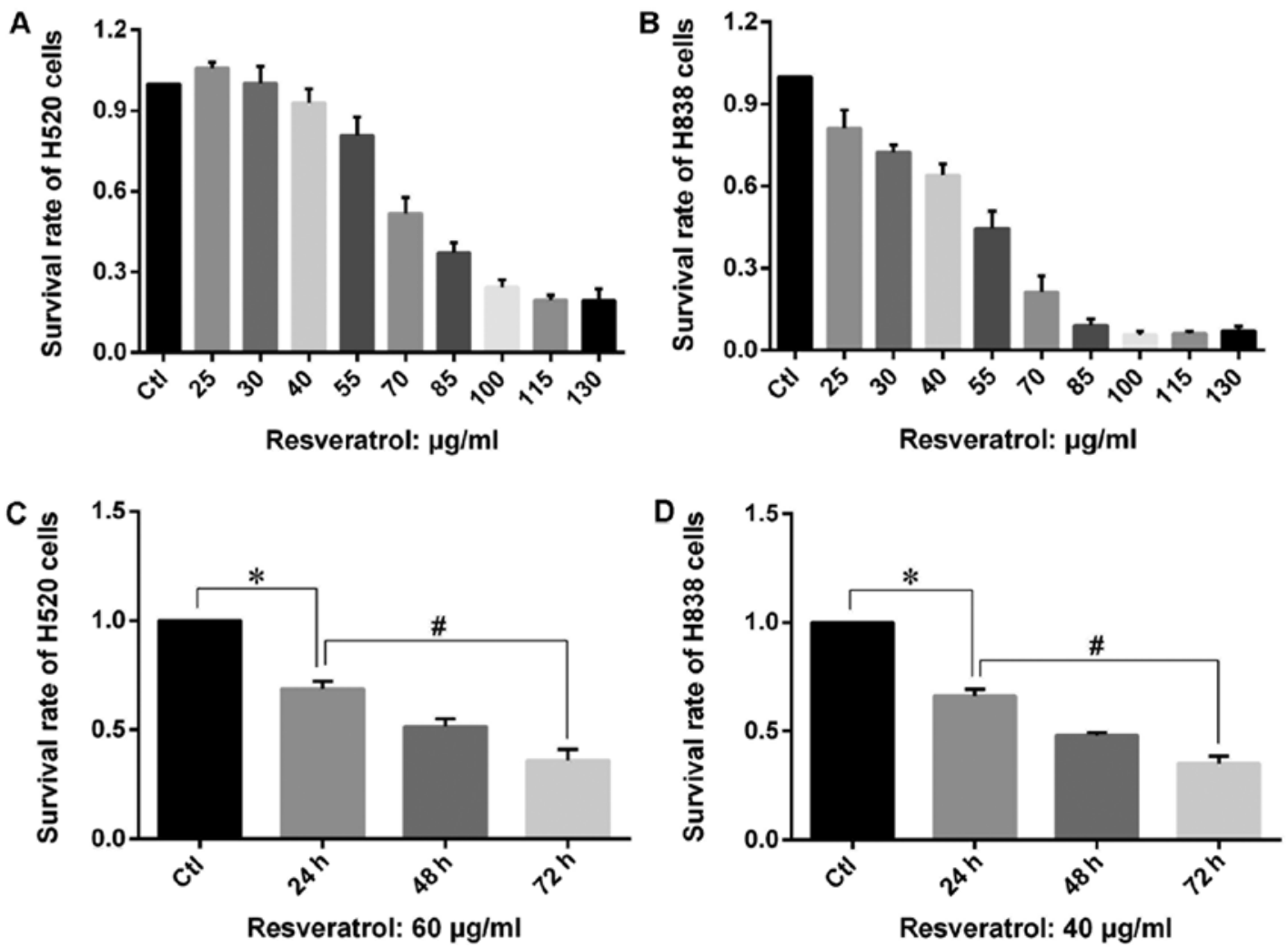

Figure 2. Effects of resveratrol on NSCLC cell proliferation determined by MTT assay. Resveratrol inhibited the proliferation of H520 and H838 cells in a dose (A and B) dependent manner after $24 \mathrm{~h}$ of exposure, $(\mathrm{C}$ and $\mathrm{D})$ showed that resveratrol treatment (marked with *) inhibited the proliferation of the two cell lines after $24 \mathrm{~h}$ treatment ${ }^{*} \mathrm{P}<0.05$; and the comparison between $24 \mathrm{~h}$ and $72 \mathrm{~h}$ treatment groups (marked with \#) revealed that prolonged exposure to resveratrol exaggerated the inhibition effects ${ }^{\#} \mathrm{P}<0.05$.

immune-reactive signals were detected by ECL detection system (Amersham Pharmacia Biotech).

Statistical analysis. Statistical analysis was performed with SPSS 17.0. Numeric variables are expressed as means \pm SD. Statistical differences among experimental conditions were performed by one-way analysis of variance (ANOVA) followed by Dunnett's test. $\mathrm{P}<0.05$ was considered to be statistically significant.

\section{Results}

Effects of resveratrol on lung cancer cell proliferation. MTT assay was carried out in order to assess the growth inhibitory effects of resveratrol on proliferation of H838 and H520 cells. The results showed that an extremely low dose of resveratrol $(<40 \mu \mathrm{g} / \mathrm{ml})$ exhibited a mild enhancing effect on the proliferation of H520 cells, while higher dose of resveratrol $(>50 \mu \mathrm{g} / \mathrm{ml})$ inhibited the proliferation of $\mathrm{H} 838$ and $\mathrm{H} 520$ cells in a dose- and time-dependent manner (Fig. 2). The MTT results also revealed that the same dose of resveratrol leads to a much stronger inhibition on growth of H838 cells compared with that of H520 cells.

Influence of resveratrol on morphology of lung cancer cells. As shown in Fig. 3A and E, cell colonies were found in normal H838 and H520 cells, and most of the normal cells were scattered in the whole field of microscope. The cell bodies of normal H838 and H520 cells were stretched in different directions, and nucleus of those normal cells stayed in the center and formed a relative dark area. The cells stimulated by resveratrol at $40 \mu \mathrm{g} / \mathrm{ml}$ in $\mathrm{H} 838$ cells and $55 \mu \mathrm{g} / \mathrm{ml}$ in H520 cells (shown in Fig. $3 \mathrm{~B}$ and F) were sparse with decreased cell number. On the other hand, single cells challenged by resveratrol exhibited cell shrinkage, condensed cytoplasm and increased percentage of the nucleus.

Resveratrol induces apoptosis in H838 and H520 cells. In order to investigate anticancer effects of resveratrol on NSCLC, H838 and H520 cells were treated with resveratrol as described in Materials and methods and the percentage of cells undergoing apoptosis were determined by flow cytometric analysis after being stained with Annexin V-FITC and PI. The results showed that resveratrol $(40 \mu \mathrm{g} / \mathrm{ml}$ for $\mathrm{H} 838$ cells and $55 \mu \mathrm{g} / \mathrm{ml}$ for H520 cells) caused apoptosis in H838 and H520 cells. Early apoptotic cells in each experimental group significantly increased compared with that of control group (Fig. 4). Although there was some difference in data from H838 and H520 cells, the results from the two cell types indicated a similar trend after being challenged by resveratrol.

Effects of resveratrol on MMP. According to the above findings, we hypothesized that the anticancer effects of resveratrol was associated with function of mitochondria. We evaluated the MMP of cells from each group stimulated by resveratrol 

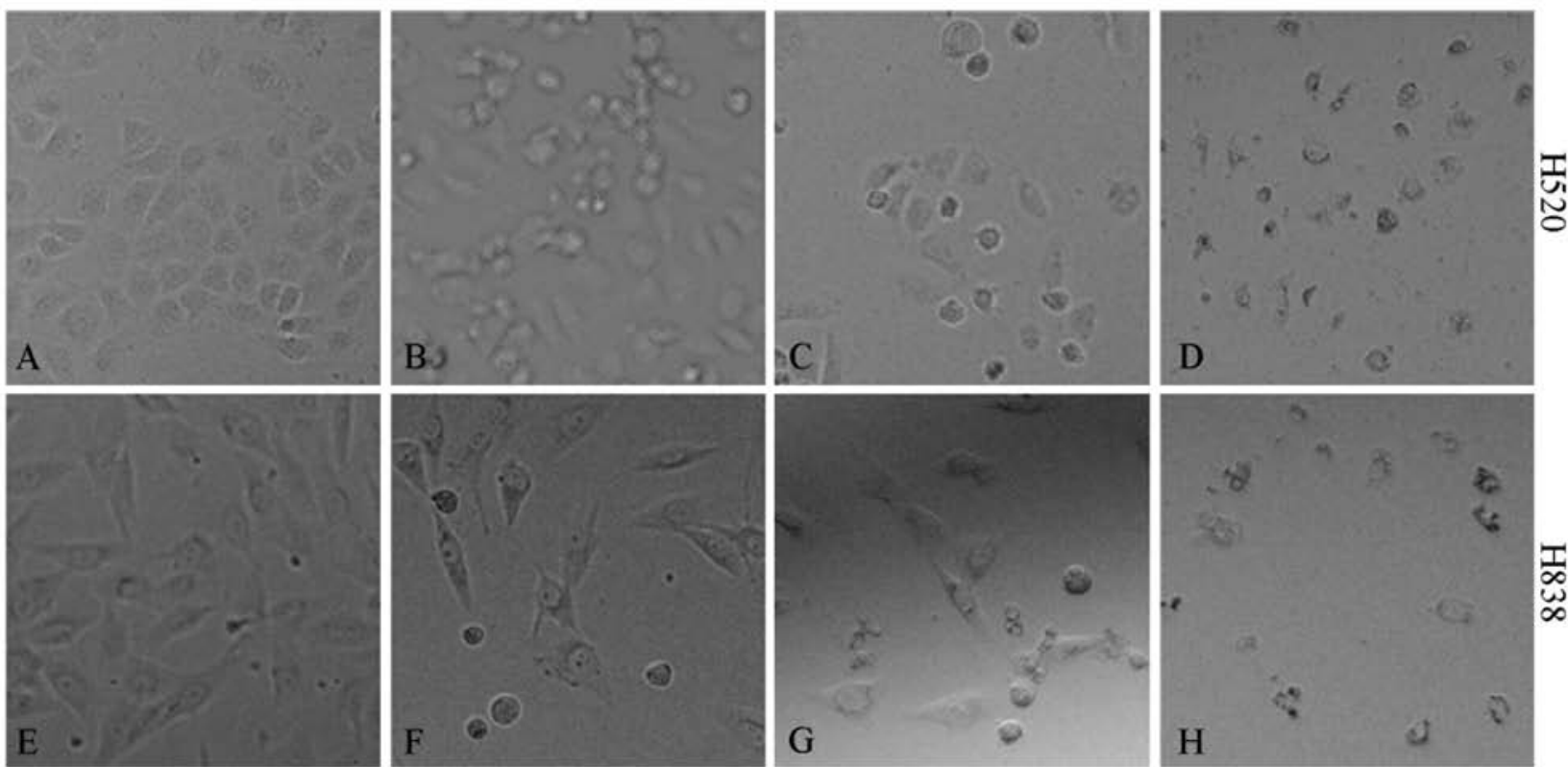

Figure 3. The morphological changes in H520 and H838 cells treated with or without resveratrol, cisplatin or combined adoption of the two agents. (A and E) Control; (B and F) Resveratrol; (C and G) Cisplatin; (D and H) Resveratrol + cisplatin.
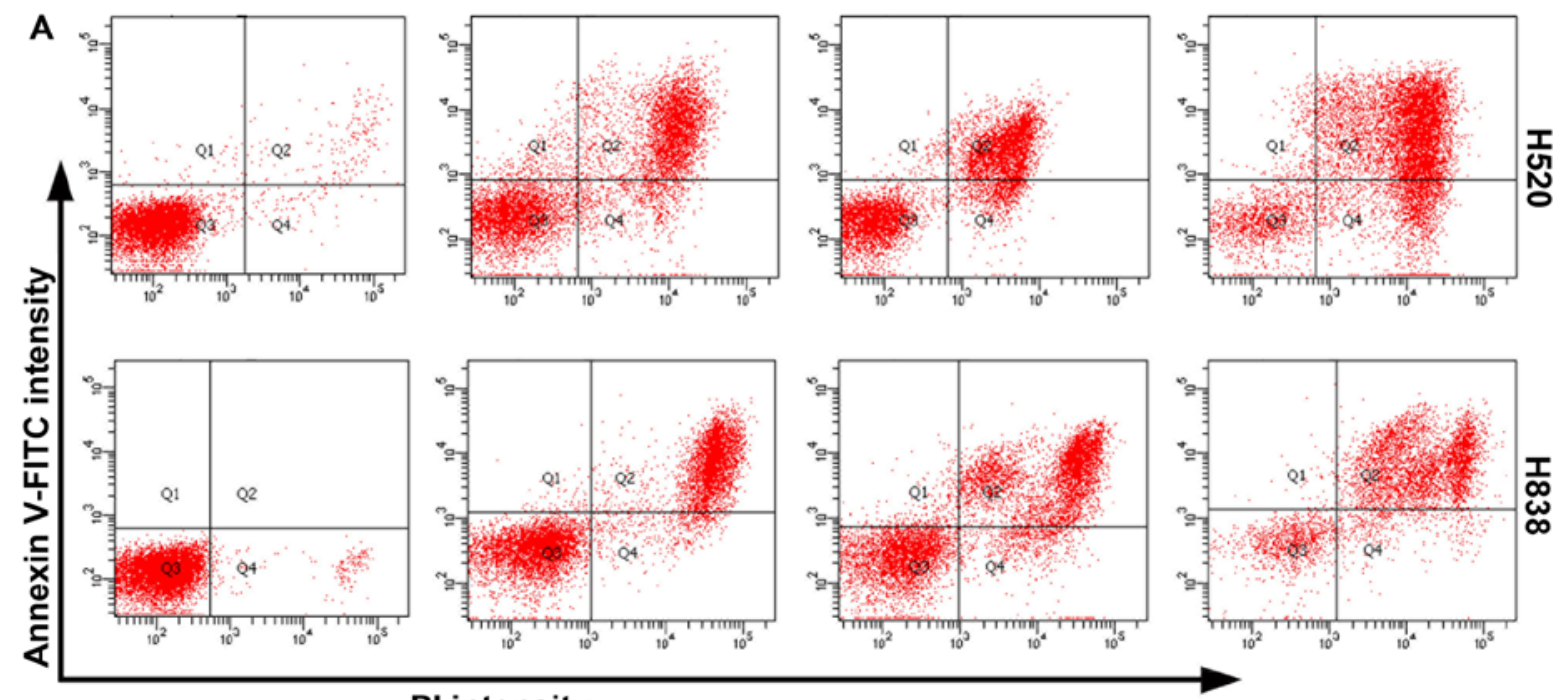

\section{PI intensity}

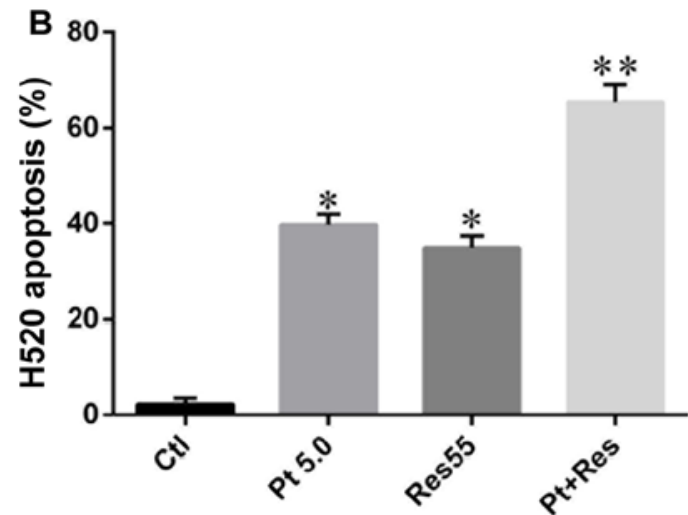

Cisplatin and Resveratrol: $\mu \mathrm{g} / \mathrm{ml}$

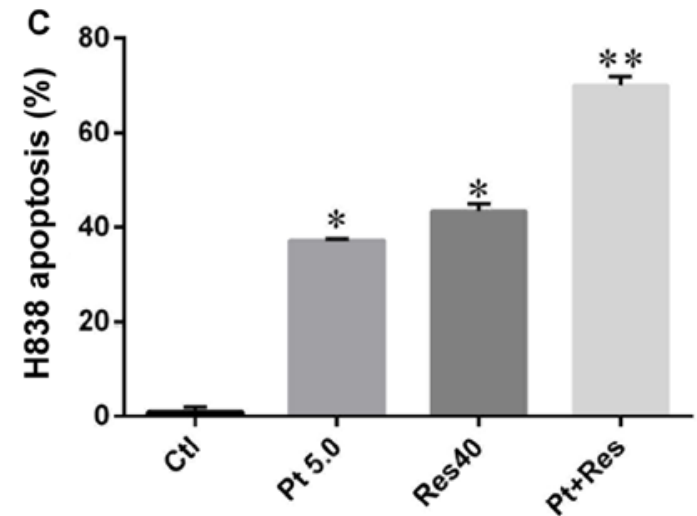

Cisplatin and Resveratrol: $\mu \mathrm{g} / \mathrm{ml}$

Figure 4. Resveratrol induced apoptosis in H520 and H838 cells was examined by flow cytometric analysis. (A) Representative flow cytometry diagram of cell apoptosis analysis. (B and C) Analysis of cell apoptosis. The results were expressed as the mean \pm SD of separate experiments. Ctl, control; Pt5.0, cisplatin 5.0 $\mu \mathrm{g} / \mathrm{ml}$; Res55, resveratrol $55 \mu \mathrm{g} / \mathrm{ml} ; \mathrm{Pt}+\mathrm{Res}$, cisplatin $5.0 \mu \mathrm{g} / \mathrm{ml}+$ resveratrol $55 \mu \mathrm{g} / \mathrm{ml}$. Comparison between individual treatment group (marked with *) and control revealed that cisplatin and resveratrol induced apoptosis in those cells ${ }^{*} \mathrm{P}<0.05 \mathrm{vs}$. Ctl; and combined treatment (marked with ** in the graph) induced more apoptosis compared with that of individual treatment groups: ${ }^{*} \mathrm{P}<0.05$ vs. ${ }^{* *} \mathrm{P}$. 

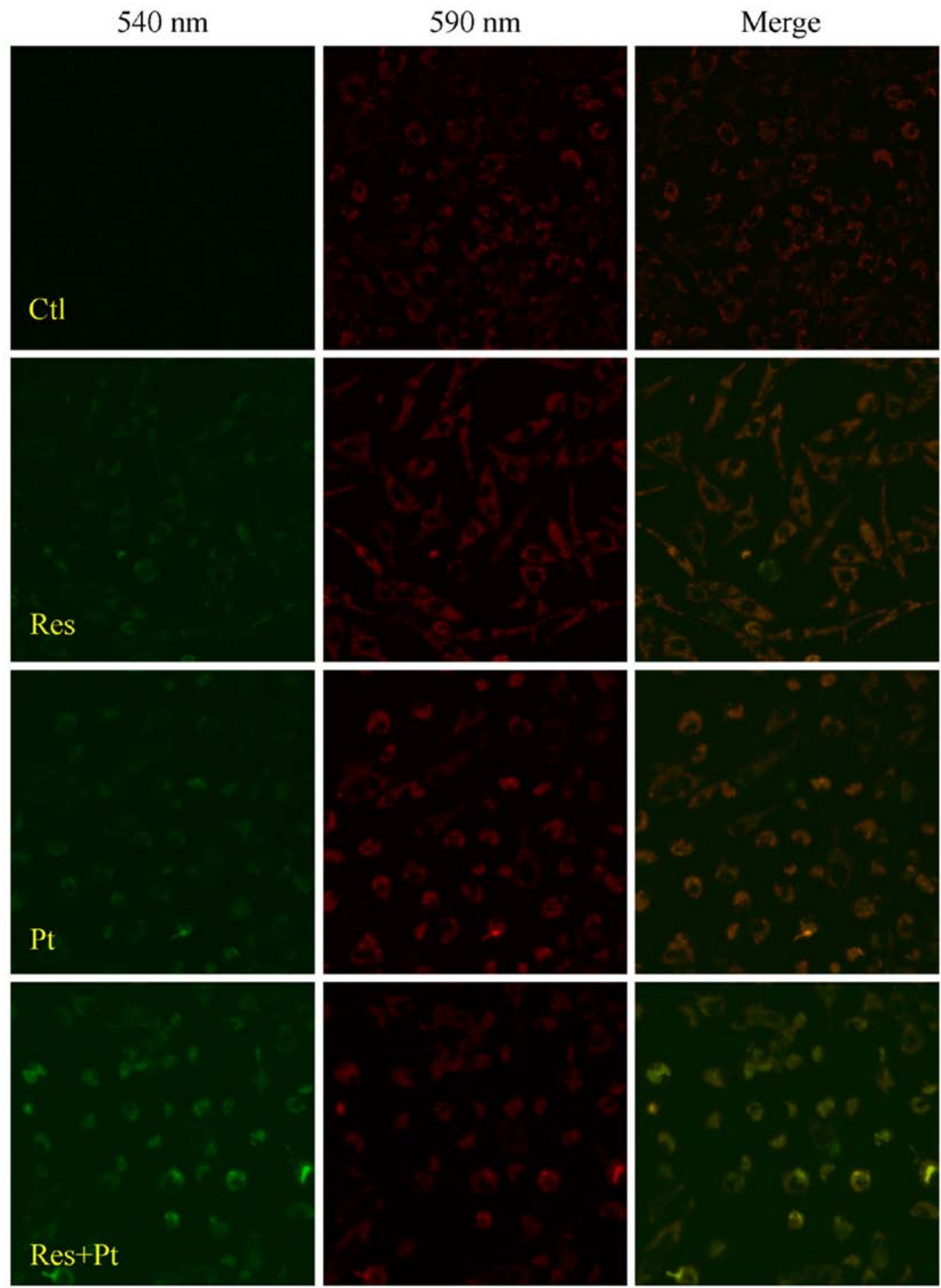

Figure 5. Depolarization of the MMP in H520 cells was evaluated by JC-1. Changes in fluorescence intensity ratio between the green light (540 $\mathrm{nm}$ ) and red light $(590 \mathrm{~nm}$ ) represent the mitochondrial membrane potential. Ctl, control; Pt, cisplatin $5.0 \mu \mathrm{g} / \mathrm{ml} ;$ Res, resveratrol $55 \mu \mathrm{g} / \mathrm{ml} ; \mathrm{Res}+\mathrm{Pt}, \mathrm{cisplatin} 5.0 \mu \mathrm{g} / \mathrm{ml}+$ resveratrol $55 \mu \mathrm{g} / \mathrm{ml}$.

$(55 \mu \mathrm{g} / \mathrm{ml})$ or not. As shown in Fig. 5, green light in H520 cells became stronger compared with that of control when stimulated by resveratrol, which meant a decreased MMP in the cells when challenged by resveratrol.

Effects of resveratrol on release of cytochrome $c$. In order to further confirm the role of mitochondria in resveratrol induced apoptosis in H838 and H520 cells, the release of cytochrome $c$ from mitochondria to cytosol was examined in H520 cells treated with different dose of resveratrol (50, 60 and $70 \mu \mathrm{g} / \mathrm{ml}$ ). The results show (Fig. 6) that the content of cytosol cytochrome $c$ increased in a dose-dependent manner.

Effects of resveratrol on the expression of apoptosis regulators. Our data showed that resveratrol-induced apoptosis was closely related to MMP depolarization. It has been broadly 


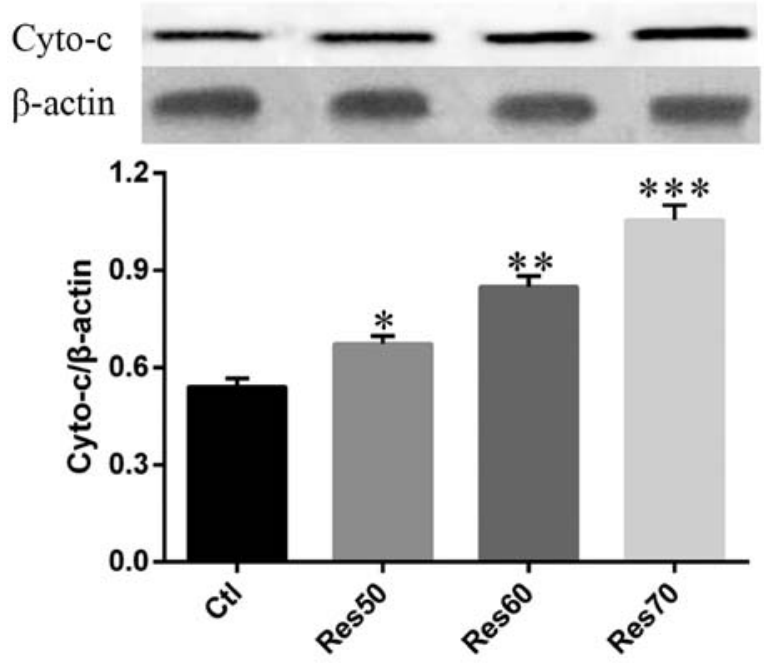

Resveratrol: $\mu \mathrm{g} / \mathrm{ml}$

Figure 6. Release of cytochrome $c$ from mitochondria into cytosol in cells treated with 50,60 or $70 \mu \mathrm{g} / \mathrm{ml}$ of resveratrol (marked with *,** and $* * *$ respectively) was assessed by western blot analysis. Relative content of cytochrome $c$ in cytosol was expressed by gray value ratio between cytochrome $c$ and $\beta$-actin Comparison between different dose group revealed that resveratrol treatment led to release of cytochrome $c$ in a dose-dependent manner ${ }^{*} \mathrm{P}<0.05$ vs. $\mathrm{Ctl}$; ${ }^{*} \mathrm{P}<0.05$ vs. ${ }^{* *} \mathrm{P},{ }^{* * *} \mathrm{P}<0.05$ vs. ${ }^{* * * * *} \mathrm{P}$.

accepted that $\mathrm{Bcl}-2$ protein family participated in the mitochondrial apoptotic pathway (14). In order to further illustrate the mechanism of resveratrol in cell apoptotic effects, we evaluated the expression of Bcl-2 family proteins in $\mathrm{H} 520$ cells treated with different dose of resveratrol $(50,60$ and $70 \mu \mathrm{g} / \mathrm{ml})$. As shown in Fig. 7. the expression of Bax was markedly increased by resveratrol compared with that of control. On the other hand, the expression of Bcl-2 was significantly decreased by resveratrol. More importantly, the expression of Bcl-2 and Bax changed in a dose-dependent manner.

Resveratrol enhances the effects of cisplatin on NSCLC cell proliferation morphological changes. After confirmation that resveratrol exhibited anticancer effects by interfering with the mitochondria-related apoptotic pathway, we evaluated whether resveratrol could enhance the anticancer effects of cisplatin. MTT assay was carried in H838 and H520 cells stimulated by cisplatin combined with or without resveratrol. As shown in Fig. 8A and B, cisplatin inhibited the proliferation of H838 and $\mathrm{H} 520$ cells in a dose-dependent manner, besides, low dose of cisplatin also suppressed H838 and H520 cell proliferation which was different from the effects of resveratrol. The combined use of cisplatin $(5 \mu \mathrm{g} / \mathrm{ml})$ and resveratrol (at $40 \mu \mathrm{g} /$ $\mathrm{ml}$ in $\mathrm{H} 838$ cells and $55 \mu \mathrm{g} / \mathrm{ml}$ in H520 cells) exhibited a much better inhibition effect on the proliferation of the cells than single usage of the two agents (Fig. 8C and D). The joint application of cisplatin and resveratrol also resulted in much more apparent morphological changes in $\mathrm{H} 838$ and H520 cells (Fig. 3D and $\mathrm{H}$ ) compared with that of cisplatin alone (Fig. 3C and $G)$.

Resveratrol enhances the effects of cisplatin on MMP and cell apoptosis. We further examined the MMP and cell apoptosis in the cells treated with cisplatin combined with or without resveratrol. Results showed that (Fig. 5) cisplatin could decrease the MMP in H520 cells and there was severe decrease in MMP in cells stimulated by cisplatin $(5 \mu \mathrm{g} / \mathrm{ml})$ combined with resveratrol $(55 \mu \mathrm{g} / \mathrm{ml})$. Cell apoptotic results also showed that resveratrol accelerated cisplatin induced apoptosis in H838 and H520 cells (Fig. 4).

Resveratrol promotes cisplatin-induced cytochrome c release. In order to validate the enhancement on the anticancer effects of resveratrol, we examined the cytosol cytochrome $c$ release in H520 cells treated with cisplatin combined with or without resveratrol. The results (Fig. 9) showed that cisplatin $(5 \mu \mathrm{g} /$ $\mathrm{ml}$ ) increased the content of cytochrome $c$ in cytosol while much more cytochrome $c$ was released into the cytosol once cells were stimulated by cisplatin combined with resveratrol $(55 \mu \mathrm{g} / \mathrm{ml})$.

Resveratrol promotes the effects of cisplatin on apoptosis regulators. The expression of Bcl-2 protein family in $\mathrm{H} 520$ cells stimulated by cisplatin, resveratrol and joint application
A
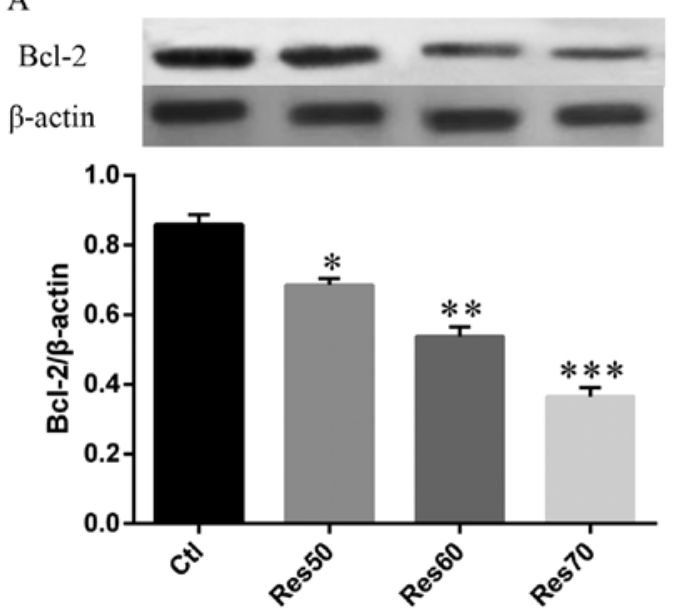

B

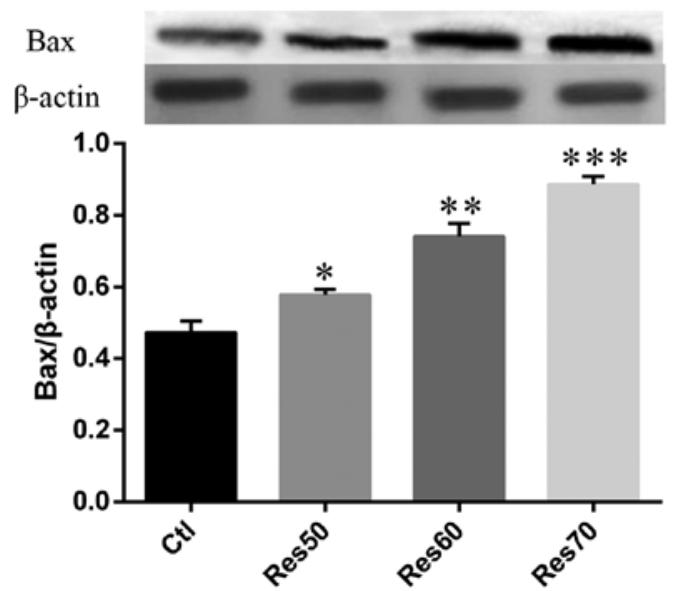

Figure 7. Expression of Bcl-2 and Bax in $\mathrm{H} 520$ cells treated with 50,60 or $70 \mu \mathrm{g} / \mathrm{ml}$ of resveratrol (marked with *, ** and $* * *$ respectively) was evaluated by western blot analysis. Relative expression levels of Bcl-2 and Bax were expressed by comparing with that of $\beta$-actin. Comparison between different dose group revealed that resveratrol treatment increased $\mathrm{Bcl}-2$ and Bax expression in a dose-dependent manner ${ }^{*} \mathrm{P}<0.05 \mathrm{vs}$. Ctl, ${ }^{*} \mathrm{P}<0.05$ vs. ${ }^{* *} \mathrm{P},{ }^{* *} \mathrm{P}<0.05$ vs. ${ }^{* * *} \mathrm{P}$. 


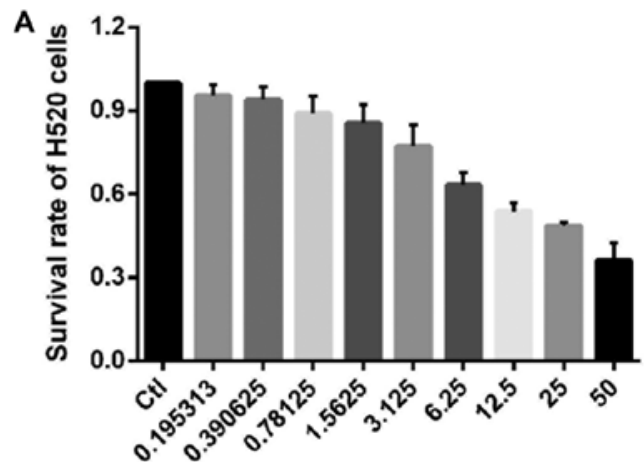

Cisplatin: $\mu \mathrm{g} / \mathrm{ml}$

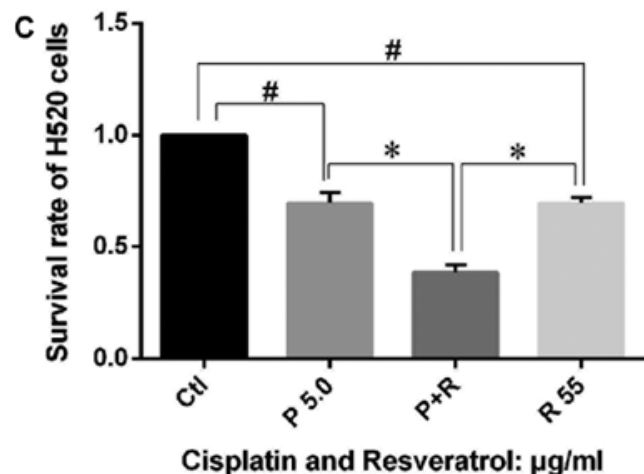

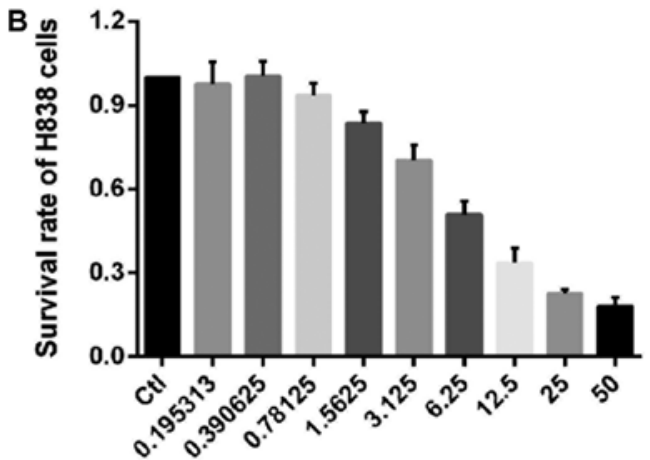

Cisplatin: $\mu \mathrm{g} / \mathrm{ml}$

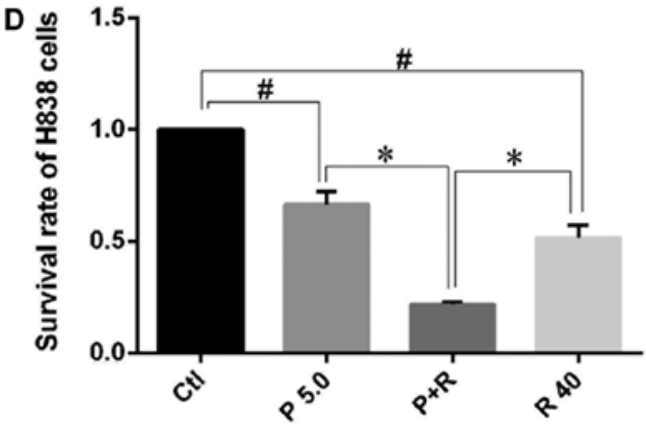

Cisplatin and Resveratrol: $\mu \mathrm{g} / \mathrm{ml}$

Figure 8. Effects of cisplatin combined with or without resveratrol on NSCLC cells were determined by MTT assay. Cisplatin inhibited the proliferation of H520 (A) and H838 (B) cells in a dose-dependent manner after $24 \mathrm{~h}$ of treatment. Comparison between individual treatment of cisplatin or resveratrol and control (marked with \#) revealed that the two agents inhibited the proliferation of H520 (C) and H838 (D) cells, "P $<0.05$; Comparison between combined treatment and individual treatment (marked with *) showed that combined adoption amplified the inhibition effects on cisplatin on NSCLC cells, ${ }^{*} \mathrm{P}<0.05$.

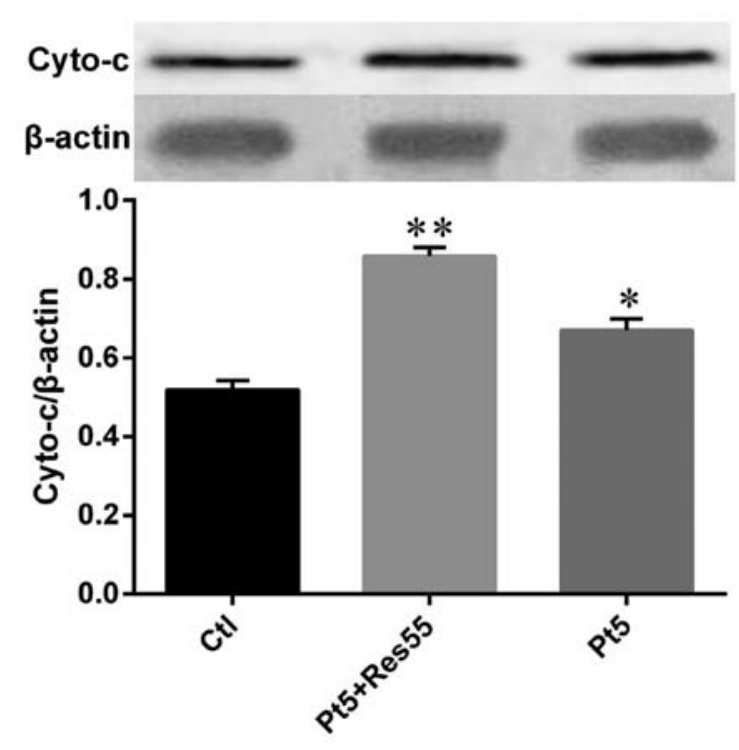

Figure 9. Release of cytochrome $c$ from mitochondria into cytosol in $\mathrm{H} 520$ cells exposed to cisplatin $(\mu \mathrm{g} / \mathrm{ml})$ combined with or without resveratrol $(\mu \mathrm{g} / \mathrm{ml})$ was assessed by western blot analysis. Cisplatin treatment (marked with *) increased the release of cytochrome $c$ compared with that of control "P<0.05 vs. Ctl; and resveratrol combination (marked with **) accelerated the enhancing effects of cisplatin on release of cytochrome ${ }^{*} \mathrm{P}<0.05$ vs. ${ }^{* *} \mathrm{P}$.

of the two agents were also evaluated by western blot analysis The results (Fig. 10) showed that both cisplatin $(5 \mu \mathrm{g} / \mathrm{ml}$ ) and resveratrol $(55 \mu \mathrm{g} / \mathrm{ml})$ decreased $\mathrm{Bcl}-2$ expression and increased the expression of Bax, while combined usage of cisplatin and resveratrol led to more marked decrease in Bcl-2 expression and resulted in more expression of Bax compared with that in cells challenged by a single agent.

\section{Discussion}

The high toxicity of anticancer drugs adopted in clinical first line therapy to normal tissues and cells is a near impassable barrier for cancer therapy. However, agents derived from various plants with few or no side effects have been recognized as potential alternative or auxiliary cure for cancer patients. Resveratrol, extracted from grape or polygonum, is such a natural compound and has been confirmed to possess anticancer potentials, reduce blood viscosity, maintaining blood flow, and inhibiting platelet aggregation $(15,16)$. Previous studies have also indicated that resveratrol enhanced the sensitivity of tumor cells to chemotherapeutic agents, which was one of the major goals in the development of auxiliary chemotherapeutic drugs (17-19). However, the mechanisms how resveratrol sensitized tumor cells to the drugs were not clearly understood.

In the present study, we investigated the inhibitory effect of resveratrol on the proliferation of non-small cell lines $\mathrm{H} 838$ and $\mathrm{H} 520$ in vitro. The results revealed that resveratrol decreased the cell viability in a dose- and time-dependent manner, besides; resveratrol treatment also induced apoptosis in the cell lines. Further examinations indicated that resvera- 

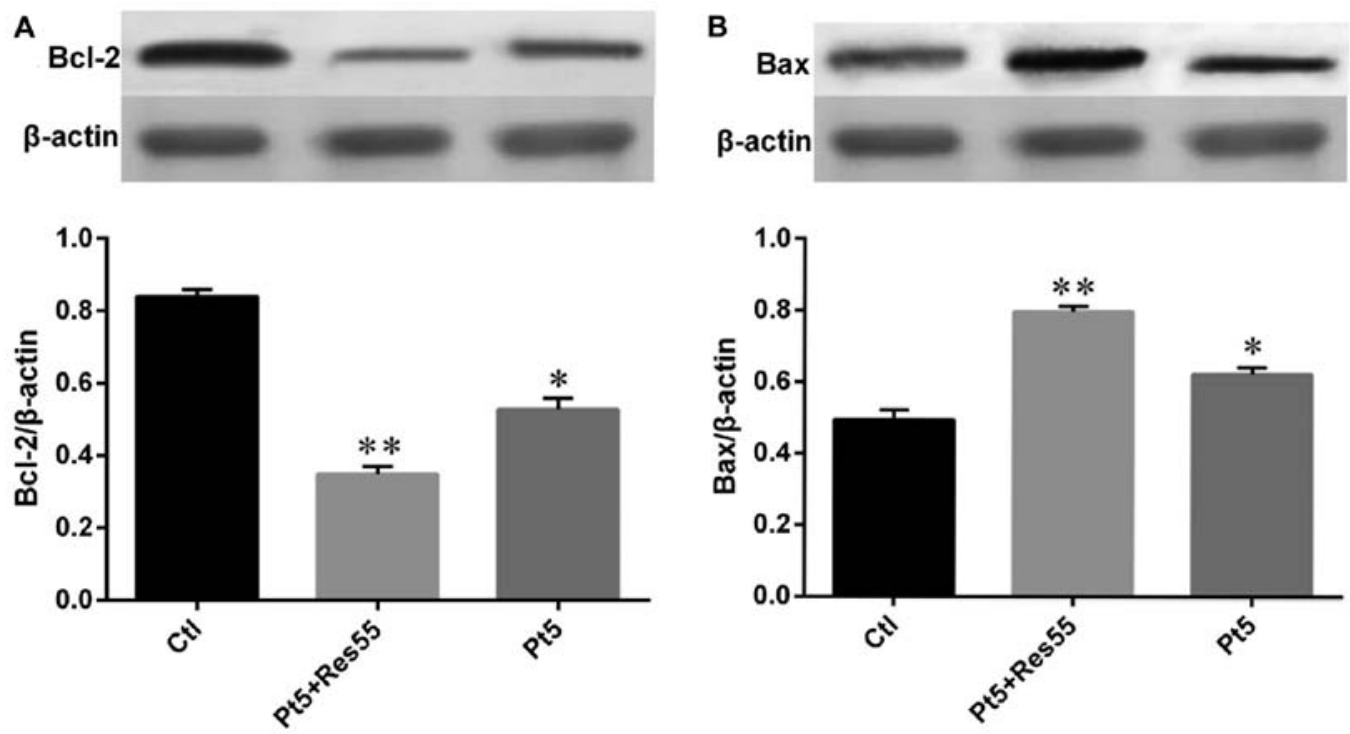

Figure 10. Expressions of Bcl-2 and Bax in H520 cells exposed to cisplatin combined with or without resveratrol were assessed by western blot analysis. Relative expression levels of Bcl-2 and Bax were expressed by comparing with that of $\beta$-actin. Cisplatin treatment (marked with *) upregulated the expression of Bcl-2 and Bax compared with that of control ${ }^{*} \mathrm{P}<0.05$ vs. Ctl, and resveratrol combination (marked with **) enhanced cisplation's effects on expression of Bcl-2 and Bax ${ }^{*} \mathrm{P}<0.05$ vs. ${ }^{* *} \mathrm{P}$.

trol could lead to depolarization of MMP, and pathway analysis showed that resveratrol increased the release of cytochrome $c$ from mitochondria to cytosol, upregulated the expression of Bax, deregulated Bcl-2 expression and finally resulted in cell apoptosis. Moreover, the results from combined use of resveratrol and cisplatin showed that resveratrol enhanced the effects of cisplatin on inhibition of cancer cell proliferation and induction of apoptosis in H838 and H520 cells. Those findings indicated that resveratrol exerted anticancer effects and made it easier for cisplatin to play its role in proliferation inhibition and apoptosis induction on non-small cell lung cancer H838 and H520 cells through mitochondrial apoptotic pathway.

Mitochondria are intracellular dynamic organelles and provide $95 \%$ of adenosine triphosphate (ATP) needed in human body which means mitochondria are essential for cells to maintain their normal functions (20). During the process of oxidative phosphorylation, energy is stored as asymmetric distribution of protons and other ions between inner and outer mitochondrial membranes which is known as mitochondrial membrane potential (MMP) $(21,22)$. Normal MMP is essential for oxidative phosphorylation and generation of ATP, and decreased MMP is the hallmark of early cell apoptosis induced by various stimuli. It has been confirmed, in the present study, that individual use of resveratrol or cisplatin decreased the MMP in H520 cells, however, combined application of the two agents dramatically upgraded the effects of cisplatin on depolarization of MMP in H520 cells. All these results indicated that resveratrol affected the biological functions of cancer cells and enhanced the effects of cisplatin in mitochondria related pathway.

Depolarization of MMP is associated with the opening of mitochondrial PTP which may lead to release of cytochrome $c$ from mitochondria to the cytosol. Cytochrome $c$ is a kind of electron transfer in oxidative phosphorylation and participates in a variety of enzymatic reaction $(23,24)$. Cytochrome $c$ released from mitochondria activated caspases and the degradation products of cleaved caspases could further increase the permeability of mitochondrial membrane, which may form a positive feedback and finally leads to cell apoptosis. Based on these clues, we evaluated the content of cytochrome $c$ in cytosol by western blot analysis. The results showed that the content of the cytochrome $c$ increased in a dose-dependent manner in resveratrol treated $\mathrm{H} 520$ cells and it was also revealed that resveratrol exaggerated the effects of cisplatin on the release of cytochrome $c$.

Previous studies have confirmed that the release of cytochrome $c$ is at least partially controlled by $\mathrm{Bcl}-2$ proteins (25). There are also studies that showed that Bcl-2 could modulate cell apoptosis even after cytochrome $c$ was released into cytosol because Bcl-2 may regulate cell apoptosis up- and downstream of cytochrome $c$ related apoptotic pathway (26). Bcl-2 family proteins are pivotal regulators for cell survival and apoptosis (27). On the one hand, Bcl-2 was the first discovered death regulator which could enhance cell survival and proliferation (28). On the other hand, Bax is an important pro-apoptosis protein which activated executors of apoptosis promoting apoptotic cell death (29). Besides, there are studies indicating that Bcl-2 protein family regulated cell apoptosis by interfering with the permeability of mitochondrial outer membrane. Moreover, the expression balance of pro-apoptosis and anti-apoptosis proteins was also essential for cell survival because apoptosis would be triggered if $\mathrm{Bcl}-2$ could not restrain the expression of Bax (30). In the present study, we evaluated the expression of Bcl-2 and Bax in the H520 cells treated with resveratrol, cisplatin or combined use of the two agents. The results revealed that resveratrol upregulated Bax expression in a dose-dependent manner and decreased expression of Bcl-2 dose-dependently, resveratrol enhanced the effects of cisplatin on the upregulation of Bax and de-regulation of Bcl-2 expression.

In conclusion, results from the present study demonstrated for the first time that resveratrol inhibited H838 and H520 cell proliferation, and induced apoptosis in NSCLC cells through 
mitochondrial apoptotic pathway. Resveratrol enhanced the proliferation inhibition and apoptosis inducing effects of cisplatin at least partially through this pathway. However, further studies are still needed to fully evaluate anticancer effects of cisplatin and phloretin combination in vivo and to assess whether resveratrol could be adopted as a novel auxiliary therapeutic in cancer treatment.

\section{Acknowledgements}

This study was supported by the National Natural Science Foundation of China (no. 81071933).

\section{References}

1. Siegel RL, Miller KD and Jemal A: Cancer statistics, 2015. CA Cancer J Clin 65: 5-29, 2015

2. Lerouge D, Riviere A, Dansin E, Chouaid C, Dujon C, Schott R, Lavole A, Le Pennec V, Fabre E, Crequit J, et al: A phase II study of cisplatin with intravenous and oral vinorelbine as induction chemotherapy followed by concomitant chemoradiotherapy with oral vinorelbine and cisplatin for locally advanced non-small cell lung cancer. BMC Cancer 14: 231, 2014.

3. Jakopovic M, Thomas A and Lopez-Chavez A: From platinum compounds to targeted therapies in advanced thoracic malignancies. Anticancer Res 34: 477-482, 2014

4. Verdecchia A, Francisci S, Brenner H, Gatta G, Micheli A, Mangone L and Kunkler I: Recent cancer survival in Europe: a 2000-02 period analysis of EUROCARE-4 data. Lancet Oncol 8: 784-796, 2007.

5. Chi YC, Lin SP and Hou YC: A new herb-drug interaction of Polygonum cuspidatum, a resveratrol-rich nutraceutical, with carbamazepine in rats. Toxicol Appl Pharmacol 263: 315-322, 2012.

6. Das S and Das DK: Resveratrol: a therapeutic promise for cardiovascular diseases. Recent Pat Cardiovasc Drug Discov 2: 133-138, 2007.

7. Demoulin B, Hermant M, Castrogiovanni C, Staudt C and Dumont P: Resveratrol induces DNA damage in colon cancer cells by poisoning topoisomerase II and activates the ATM kinase to trigger p53-dependent apoptosis. Toxicol In Vitro 29: $1156-1165,2015$.

8. Narayanan BA, Narayanan NK, Re GG and Nixon DW: Differential expression of genes induced by resveratrol in $\mathrm{LNCaP}$ cells: P53-mediated molecular targets. Int J Cancer 104: 204-212, 2003.

9. Stewart JR, Ward NE, Ioannides CG and O'Brian CA: Resveratrol preferentially inhibits protein kinase $\mathrm{C}$-catalyzed phosphorylation of a cofactor-independent, arginine-rich protein substrate by a novel mechanism. Biochemistry 38: 13244-13251, 1999.

10. Tinhofer I, Bernhard D, Senfter M, Anether G, Loeffler M, Kroemer G, Kofler R, Csordas A and Greil R: Resveratrol, a tumor-suppressive compound from grapes, induces apoptosis via a novel mitochondrial pathway controlled by Bcl-2. FASEB J 15: $1613-1615,2001$.

11. Mahyar-Roemer M, Kohler $\mathrm{H}$ and Roemer K: Role of Bax in resveratrol-induced apoptosis of colorectal carcinoma cells. BMC Cancer 2: 27, 2002.

12. Fontecave M, Lepoivre M, Elleingand E, Gerez C and Guittet O: Resveratrol, a remarkable inhibitor of ribonucleotide reductase. FEBS Lett 421: 277-279, 1998

13. Ly JD, Grubb DR and Lawen A: The mitochondrial membrane potential (deltapsi(m)) in apoptosis; an update. Apoptosis 8: $115-128,2003$.

14. Porter AG and Janicke RU: Emerging roles of caspase-3 in apoptosis. Cell Death Differ 6: 99-104, 1999.
15. Wightman EL, Reay JL, Haskell CF, Williamson G, Dew TP and Kennedy DO: Effects of resveratrol alone or in combination with piperine on cerebral blood flow parameters and cognitive performance in human subjects: a randomised, double-blind, placebo-controlled, cross-over investigation. Br J Nutr 112: 203-213, 2014

16. Kennedy DO, Wightman EL, Reay JL, Lietz G, Okello EJ, Wilde A and Haskell CF: Effects of resveratrol on cerebral blood flow variables and cognitive performance in humans: a doubleblind, placebo-controlled, crossover investigation. Am J Clin Nutr 91: 1590-1597, 2010

17. Aires V, Limagne E, Cotte AK, Latruffe N, Ghiringhelli F and Delmas D: Resveratrol metabolites inhibit human metastatic colon cancer cells progression and synergize with chemotherapeutic drugs to induce cell death. Mol Nutr Food Res 57: 1170-1181, 2013.

18. Mikstacka R and Ignatowicz E: Chemopreventive and chemotherapeutic effect of trans-resveratrol and its analogues in cancer. Pol Merkur Lekarski 168: 496-500, 2010 (In Polish).

19. Frampton GA, Lazcano EA, Li H, Mohamad A and DeMorrow S: Resveratrol enhances the sensitivity of cholangiocarcinoma to chemotherapeutic agents. Lab Invest 90: 1325-1338, 2010.

20. Hamada M, Sumida M, Okuda H, Watanabe T, Nojima M and Kuby SA: Adenosine triphosphate-adenosine-5'-monophosphate phosphotransferase from normal human liver mitochondria. Isolation, chemical properties, and immunochemical comparison with Duchenne dystrophic serum aberrant adenylate kinase. J Biol Chem 257: 13120-13128, 1982.

21. Lei T, Guo N, Tan MH and Li YF: Effect of mouse oocyte vitrification on mitochondrial membrane potential and distribution. J Huazhong Univ Sci Technolog Med Sci 34: 99-102, 2014.

22. Diaz G, Setzu MD, Zucca A, Isola R, Diana A, Murru R, Sogos V and Gremo F: Subcellular heterogeneity of mitochondrial membrane potential: relationship with organelle distribution and intercellular contacts in normal, hypoxic and apoptotic cells. J Cell Sci 112: 1077-1084, 1999.

23. Kosekova G, Mitovska M,Minkov I, Dancheva K and Atanasov B: Effect of di-substituted cytochrome $\mathrm{C}$ pyridoxal phosphate on oxidative phosphorylation in cytochrome C-deficient liver mitochondria. Eksp Med Morfol 20: 12-17, 1981 (In Bulgarian).

24. Wilson DF and Vinogradov SA: Mitochondrial cytochrome $c$ oxidase: mechanism of action and role in regulating oxidative phosphorylation. J Appl Physiol 117: 1431-1439, 2014.

25. Gleichmann M, Beinroth S, Reed JC, Krajewski S, Schulz JB, Wullner U, Klockgether T and Weller M: Potassium deprivationinduced apoptosis of cerebellar granule neurons: cytochrome $c$ release in the absence of altered expression of Bcl-2 family proteins. Cell Physiol Biochem 8: 194-201, 1998.

26. Karabay AZ, Aktan F, Sunguroglu A and Buyukbingol Z: Methylsulfonylmethane modulates apoptosis of LPS/ IFN-gamma-activated RAW 264.7 macrophage-like cells by targeting $\mathrm{p} 53, \mathrm{Bax}, \mathrm{Bcl}-2$, and PARP proteins. Immunopharmacol Immunotoxicol 36: 379-389, 2014.

27. Rong Y and Distelhorst CW: Bcl-2 protein family members: versatile regulators of calcium signaling in cell survival and apoptosis. Annu Rev Physiol 70: 73-91, 2008.

28. Anvekar RA, Asciolla JJ, Missert DJ and Chipuk JE: Born to be alive: a role for the BCL-2 family in melanoma tumor cell survival, apoptosis, and treatment. Front Oncol 1: 34, 2011.

29. Yan W, Suominen J, Samson M, Jegou B and Toppari J: Involvement of Bcl-2 family proteins in germ cell apoptosis during testicular development in the rat and pro-survival effect of stem cell factor on germ cells in vitro. Mol Cell Endocrinol 165: 115-129, 2000.

30. Fletcher JI, Meusburger S, Hawkins CJ, Riglar DT, Lee EF, Fairlie WD, Huang DC and Adams JM: Apoptosis is triggered when prosurvival Bcl-2 proteins cannot restrain Bax. Proc Natl Acad Sci USA 105: 18081-18087, 2008. 